University of Nebraska - Lincoln

DigitalCommons@University of Nebraska - Lincoln

Papers in Veterinary and Biomedical Science

Veterinary and Biomedical Sciences

Department of

May 1993

\title{
Rapid Assessment of Drug Susceptibilities of Mycobacterium tuberculosis by Means of Luciferase Reporter Phages
}

William R. Jacobs Jr.

Howard Hughes Medical Institute, Albert Einstein College of Medicine, Bronx, NY

Raul G. Barletta

University of Nebraska - Lincoln, rbarletta1@unl.edu

Rupa Udani

Howard Hughes Medical Institute, Albert Einstein College of Medicine, Bronx, NY

John Chan

Howard Hughes Medical Institute, Albert Einstein College of Medicine, Bronx, NY

Gary Kalkut

Howard Hughes Medical Institute, Albert Einstein College of Medicine, Bronx, NY

See next page for additional authors

Follow this and additional works at: https://digitalcommons.unl.edu/vetscipapers

Part of the Veterinary Medicine Commons

Jacobs, William R. Jr.; Barletta, Raul G.; Udani, Rupa; Chan, John; Kalkut, Gary ; Sosne, Gabriel; Kieser, Tobias; Sarkis, Gary J.; Hatfull, Graham F.; and Bloom, Barry R., "Rapid Assessment of Drug Susceptibilities of Mycobacterium tuberculosis by Means of Luciferase Reporter Phages" (1993). Papers in Veterinary and Biomedical Science. 72.

https://digitalcommons.unl.edu/vetscipapers/72

This Article is brought to you for free and open access by the Veterinary and Biomedical Sciences, Department of at DigitalCommons@University of Nebraska - Lincoln. It has been accepted for inclusion in Papers in Veterinary and Biomedical Science by an authorized administrator of DigitalCommons@University of Nebraska - Lincoln. 


\section{Authors}

William R. Jacobs Jr., Raul G. Barletta, Rupa Udani, John Chan, Gary Kalkut, Gabriel Sosne, Tobias Kieser, Gary J. Sarkis, Graham F. Hatfull, and Barry R. Bloom 


\title{
Rapid Assessment of Drug Susceptibilities of Mycobacterium tuberculosis by Means of Luciferase Reporter Phages
}

\author{
William R. Jacobs, Jr.*, Raul G. Barletta ${ }^{\dagger}$, Rupa Udani, John \\ Chan, Gary Kalkut, Gabriel Sosne, Tobias Kieser, Gary J. \\ Sarkis, Graham F. Hatfull, Barry R. Bloom
}

W. R. Jacobs, Jr., R. G. Barletta, R. Udani, J. Chan, G. Kalkut, G. Sosne, B. R. Bloom, Howard Hughes Medical Institute, Albert Einstein College of Medicine, Bronx, NY 10461.

T. Kieser, John Innes Institute and AFRC Institute of Plant Science Research, Norwich NR4 7UH, United Kingdom.

G. J. Sarkis and G. F. Hatfull, Department of Biological Sciences, University of Pittsburgh, Pittsburgh, PA 15230.

* Corresponding author.

† Present address: Center for Biotechnology, Department of Veterinary and Biomedical Sciences, University of Nebraska-Lincoln, Lincoln, NE 68583

\begin{abstract}
Effective chemotherapy of tuberculosis requires rapid assessment of drug sensitivity because of the emergence of multidrug-resistant Mycobacterium tuberculosis. Drug susceptibility was assessed by a simple method based on the efficient production of photons by viable mycobacteria infected with specific reporter phages expressing the firefly luciferase gene. Light production was dependent on phage infection, expression of the luciferase gene, and the level of cellular adenosine triphosphate. Signals could be detected within minutes after infection of virulent $M$. tuberculosis with reporter phages. Culture of conventional strains with antituberculosis drugs, including isoniazid or rifampicin, resulted in extinction of light production. In contrast, light signals after luciferase reporter phage infection of drug-resistant strains continued to be produced. Luciferase reporter phages may help to reduce the time required for establishing antibiotic sensitivity of $M$. tuberculosis strains from weeks to days and to accelerate screening for new antituberculosis drugs.
\end{abstract}

Published in Science, New Series, Vol. 260, No. 5109. (May 7, 1993), pp. 819-822. Copyright (c) 1993 American Association for the Advancement of Science. Used by permission.
$\mathrm{T}$ uberculosis remains the largest cause of death in the world from a single infectious disease (1) and accounts for as much as $40 \%$ of deaths in human immunodeficiency virus (HIV)coinfected individuals in some developing countries (2). Infection with conventional M. tuberculosis can effectively be cured with a combination of antituberculosis drugs. Ominously, multidrug-resistant tuberculosis (MDR-TB) strains have emerged in several countries, with case fatalities ranging from 40 to $60 \%$ in immunocompetent individuals and $>80 \%$ in immunocompromised individuals (3). However, because M. tuberculosis has a doubling time of 20 to 24 hours, current methodology does not allow determination of drug susceptibility for 2 to 18 weeks $(4,5)$, leaving patients, contacts, and health care workers at risk.

Firefly luciferase represents one of the most efficient available biological reporter molecules because it catalyzes the reaction of luciferin with adenosine triphosphate (ATP) to generate photons with a quantum yield of 0.85 photons per molecule of substrate reacted (6). Because of the availability of a variety of sensitive light-detection systems, luciferase has become the standard assay for measuring ATP (7). Since the molecular cloning of its cDNA (8), the firefly luciferase gene has been used directly as a molecular reporter in cells of a variety of animal, plant, and bacterial species (9). We reasoned that the expression of luciferase activity could serve as a sensitive in vivo measure of ATP in mycobacteria and thus allow us to rapidly test cellular viability of $M$. tuberculosis after its exposure to different antimycobacterial agents. The optimal use the gene could be realized if the lucifer- 
ase activity could be measured directly, without the need for lysing of the mycobacterial cells. To ascertain whether the substrate, luciferin, could be transported across the intact mycobacterial cell wall, we cloned the firefly luciferase (FFlux) gene downstream of the heat shock protein $60(h s p 60)$ promoter in a mycobacterial extrachromosomal plasmid vector (10) and downstream of the gene 71 promoter of mycobacteriophage L5 (11) in a mycobacterial integrating vector (12) (Fig. 1A). Both luciferase constructs were electroporated into Mycobacterium smegmatis (which multiplies ten times faster than M. tuberculosis), and luciferase activity was measured in cells grown to logarithmic phase. On addition of
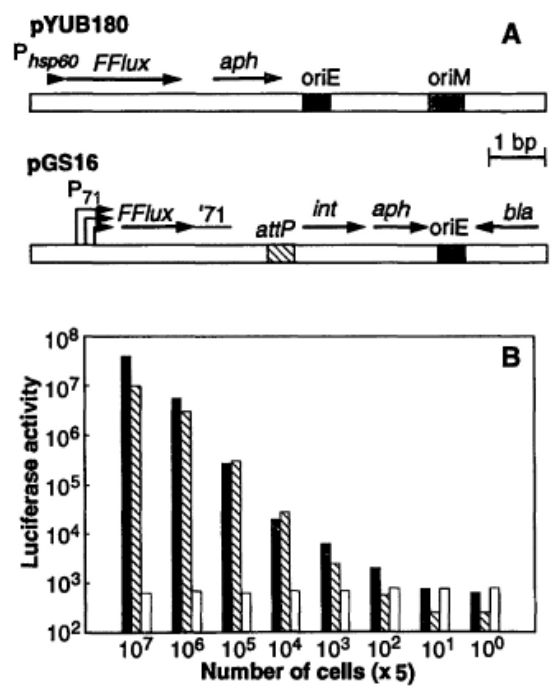

Figure 1. (A) Expression of firefly luciferase in mycobacteria. Schematic of the extrachromosomal plasmid pYUB180 and the integration plasmid pGS16. Abbreviations are as follows: $P_{\text {hsp60 }}$, promoter of the BCG $h s p 60$ gene; $P_{71}$, promoters of the mycobacteriophage L5's gene 71; FFlux, firefly luciferase gene; aph, aminoglycoside phosphotransferase that confers kanamycin resistance; oriE, ColE1 origin of replication; oriM, mycobacterial plasmid pAL5000 origin of replication; attP and int, L5 integration genes; and bla, $\beta$-lactamase that confers ampicillin resistance to $E$. coli. (B) Sensitivity of $M$. smegmatis cells expressing luciferase. Plasmids pYUB180 and pGSI6 were electroporated into the $M$. smegmatis strain $\mathrm{mc}^{2} 155$ (17). Kanamycin-resistant transformants were grown to a density of approximately $5 \times 10^{8}$ cells per milliliter, and tenfold serial dilutions were prepared. Samples $(100 \mu \mathrm{l})$ were mixed with $250 \mu \mathrm{l}$ of $0.1 \mathrm{M}$ sodium citrate $(\mathrm{pH} 5)$ in a 13 by $75 \mathrm{~mm}$ polystyrene tube. This mixture was placed in the luminometer (Monolight 2010; Analytical Luminescence Laboratory, San Diego, California), $100 \mu \mathrm{l}$ of $1 \mathrm{mM}$ luciferin (Sigma, St. Louis, Missouri) was injected into the tube, and the luciferase activity was measured. Mycobacterium smegmatis cultures are indicated as follows: $\mathrm{mc}^{2} 155$ (pYUB180), black; $\mathrm{mc}^{2} 155$ (pGS16), diagonal; and $\mathrm{mc}^{2} 155$ cells alone, white.

Figure 2. Infection of mycobacteria with LRPs results in the production of light. (A) Schematic of the luciferase reporter mycobacteriophages phAE39 and phAE40. Luciferase reporter phages were made by construction of shuttle phasmids in which an E. coli cosmid pYUB216 (18) was inserted into a nonessential region of the mycobacteriophage TM4. The cosmid pYUB216 contains (i) FFlux in a transcriptional fusion with the $h s p 60$ promoter of BCG, (ii) a ColE1 origin and an ampicillin resistance gene $(A p)$ for replication and selection in $E$. coli, (iii) a bacteriophage $\lambda$ cos sequence, and (iv) a unique Bcl I site. The phAE39 shuttle phasmid was constructed in a manner similar to that described previously (14), with Bcl Idigested pYUB216 ligated to TM4 DNA that had been partially digested by SAU $3 \mathrm{Al}$. The resulting shuttle phasmid, phAE39, like its parent TM4, readily forms plaques of $M$. tuberculosis, but does not efficiently form plaques on BCG. Spontaneous host range mutants of phAE39 could be isolated at frequencies of $10^{-6}$ to $10^{-7}$, and one such mutant was isolated and designated phAE40.
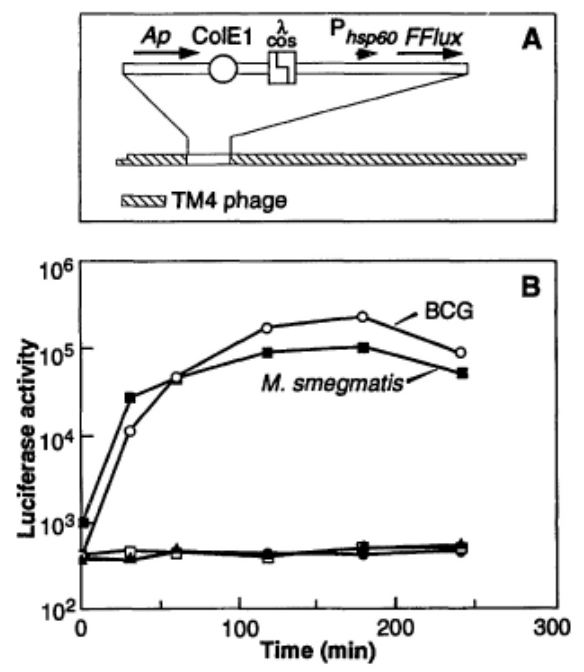

(B) Light production in mycobacteria after infection with the luciferase reporter phage phAE40. High titers of phAE40 were prepared as described previously for TM4 phages (19). Mycobacterium smegmatis, mc ${ }^{2} 155$ cells, and BCG-Pasteur cells were grown in roller bottles to approximately $5 \times 10^{7}$ cells per milliliter in Middlebrook 7H9 broth with ADC enrichment and 0.05\% Tween-80 [M-ADC-TW broth (19)] at $37^{\circ} \mathrm{C}$. Either the $M$. smegmatis or the BCG cells were harvested by centrifugation and washed twice in M-ADC broth (containing no Tween-80). The resulting pellet was resuspended in the original volume of M-ADC broth. The cells were diluted fivefold into fresh M-ADC broth and were allowed to incubate overnight standing at $37^{\circ} \mathrm{C}$. (Tween- 80 seems to remove the receptors, and we have found that optimal activities are attained if the cells have a chance to grow in the absence of Tween-80. This procedure possibly allows regeneration of phage receptors.) One milliliter of washed cells (approximately $5 \times 10^{7}$ cells) was mixed with $0.1 \mathrm{ml}$ of phAE40 particles $\left[5 \times 10^{8}\right.$ plaque-forming units (PFU) per milliliter] that had been concentrated on $\mathrm{CsCl}$ gradients to attain a multiplicity of infection of 10 . The cell-phage mixture was incubated at $37^{\circ} \mathrm{C}$. Beginning at the time of the addition of the phAE40, we removed $0.1-\mathrm{ml}$ samples at the times designated in the graph. Luciferase activity was measured as described in Figure 1 and plotted. Filled circles, BCG cells alone; open circles, BCG cells plus phAE40; filled triangles, mc ${ }^{2} 155$ cells alone; filled squares, $\mathrm{mc}^{2} 155$ cells plus phAE40; open squares, phAE40 alone.

Figure 3. Comparison of the kinetics of light production of drug-sensitive BCG cells to that of drug-resistant BCG mutant cells after phage infection. Spontaneous mutants of BCG-Pasteur strains were isolated on Middlebrook 7H10 agar containing either rifampicin $(50 \mu \mathrm{g} / \mathrm{ml})$, streptomycin $(250 \mu \mathrm{g} / \mathrm{ml})$, or isoniazid $(5 \mu \mathrm{g} / \mathrm{ml})$. The rifampicin-, streptomycin-, or isoniazid-resistant mutants were purified and designated as $\mathrm{mc}^{2} 768, \mathrm{mc}^{2} 767$, and $\mathrm{mc}^{2} 765$, respectively. All three mutants and the BCG parent were grown to midlogarithmic phase, harvested, and washed as described in Figure 2 BCG cells (circles) and mutant cells (squares) were incubated in the presence (open symbols) or absence (filled symbols) of rifampicin, streptomycin, or isoniazid. (A) The $\mathrm{mc}^{2} 768$ cells and the BCG cells were incubated standing at $37^{\circ} \mathrm{C}$ in the presence or absence of rifampicin $(50 \mu \mathrm{g} / \mathrm{ml})$ for 24 hours. A $0.5-\mathrm{ml}$ sample (approximately $5 \times 10^{7}$ viable cells) was mixed with $0.1 \mathrm{ml}$ $\left(5 \times 10^{8} \mathrm{PFU}\right)$ of phAE40 particles, and luciferase activity was determined as described in Figure 2 and plotted as a representative experiment. This experiment was repeated a minimum of three times. The absolute background and peak luminescence signals varied approximately twofold between experiments, but the ratios of signals of drug-resistant relative to susceptible cells were constant (20- to 100 -fold depending on the strain). (B) The $\mathrm{mc}^{2} 767$ cells and the BCG cells were incubated standing at $37^{\circ} \mathrm{C}$ in the presence or absence of streptomycin $(250 \mu \mathrm{g} / \mathrm{ml})$ for 24 hours. (C) The $\mathrm{mc}^{2} 765$ cells and the BCG cells were incubated standing at $37^{\circ} \mathrm{C}$ in the presence or absence of isoniazid $(50 \mu \mathrm{g} / \mathrm{ml})$ for 24 hours.
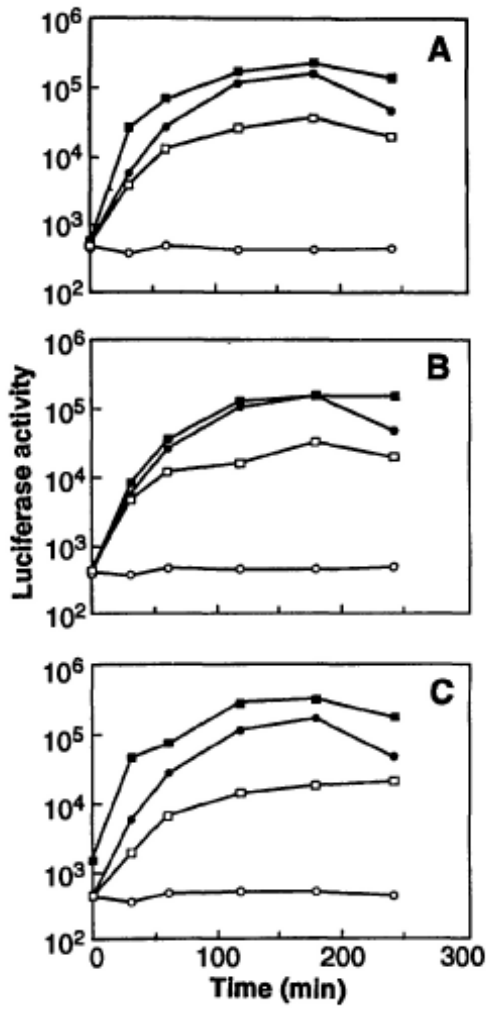
Figure 4. Use of luciferase reporter phage assay to distinguish drug-sensitive from drug-resistant $M$. tuberculosis strains. The following M. tuberculosis strains were grown in a biological safety level 3 containment facility: (i) The virulent drug-sensitive $M$. tuberculosis Erdman strain; (ii) strain 92-2025, a singly isoniazid-resistant strain; and (iii) an MDR strain of tuberculosis that has been shown to be resistant to rifampicin, streptomycin, isoniazid, ethambutol, and ethionamide and the cause of several nosocomial outbreaks in New York City (20). The Erdman strain was subcultured from the starter culture by inoculation of $0.4 \mathrm{ml}$ into $20 \mathrm{ml}$ of Middlebrook 7H9 broth containing OADC enrichment (Difco Laboratories, Detroit, Michigan) plus 0.5 Tween-80 (M-OADCTW broth). The 92-2025 and the MDR strains, which grow more slowly than the Erdman strain, were subcultured by inoculation of $2 \mathrm{ml}$ into $20 \mathrm{ml} \mathrm{M-OADC}$ TW broth. All three cultures were grown standing at $37^{\circ} \mathrm{C}$ for 7 to 8 days. The cells were washed as described above and 0.5 . resuspended in $0.5 \times$ the original volume. Washed cells $(0.2 \mathrm{ml})$ were inoculated into $0.7 \mathrm{ml}$ of M-OADC broth (19) and incubated in 13 by $100 \mathrm{~mm}$ polypropylene tubes in a heat-

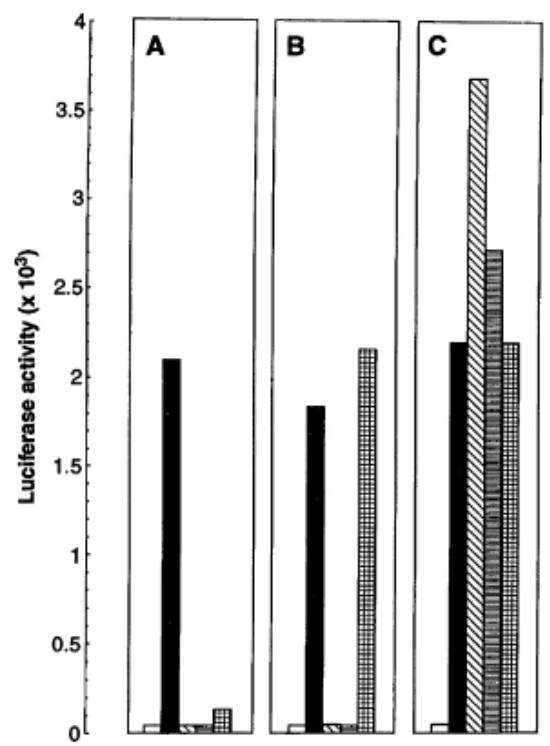

ing block in a biohazard hood for 48 hours. Rifampicin, streptomycin, or isoniazid were added to final concentrations of $2 \mu \mathrm{g} / \mathrm{ml}, 6 \mu \mathrm{g} / \mathrm{ml}$, and $1 \mu \mathrm{g} / \mathrm{ml}$, respectively. After 48 hours of incubation, $0.1 \mathrm{ml}$ of phAE40 particles $\left(1 \times 10^{11}\right.$ particles) were added to attain a multiplicity of infection of 1000 . Samples of $100 \mu \mathrm{l}$ were removed at 1,3 , and 5 hours after addition of the phage and were mixed with $250 \mu \mathrm{l}$ of 0.1 M sodium citrate ( $\mathrm{pH} 5$ ) in a Lumacuvette (Lumac BV, Netherlands). One hundred microliters of $1 \mathrm{mM}$ luciferin were added, and the Lumacuvette was plugged with cotton. The tube was placed in a Lumac Biocounter (M1500 P), and readings were recorded as described above. (The Lumac biocounter has dimensions that permit it to fit in a standard biohazard hood.) The light production followed kinetics similar to the BCG experiments, and the readings at 3 and 5 hours differed by no more than twofold. The results at 3 hours are shown for the Erdman (A), 92-2025 (B), and the MDR (C) M. tuberculosis strains. A repeated experiment gave similar results, with the samples cultured in the absence of drug exhibiting an 80-fold greater luminescence than the cells cultured with rifampicin or streptomycin and greater than tenfold luminescence relative to those cultured with isoniazid at 3 and 5 hours. Open bars, cells alone; filled bars, cells plus LRPs; diagonal lines, cells plus rifampicin plus LRPs; cross-hatching, cells plus streptomycin plus LRPs; squares, cells plus isoniazid plus LPRs.

luciferin, luciferase activity was readily measured from intact mycobacterial cells infected with both the extrachromosomal and the integrating vectors (Fig. 1B). Serial dilutions indicated that it was possible to detect as few as 500 to 5000 M. smegmatis cells expressing firefly luciferase (Fig. 1B), establishing that the luciferase-luciferin system could be developed as a sensitive reporter system for ATP in mycobacteria.

The ability to make use of the luciferase reporter gene to assess drug susceptibilities in clinical isolates requires an efficient means for delivering the luciferase gene into the $M$. tuberculosis cells. Phages offer an ideal vehicle with which to deliver a foreign gene to every cell in a bacterial culture (13). We have previously developed shuttle phasmid vectors from a variety of mycobacteriophages that can be genetically manipulated in Escherichia coli and then used to deliver the recombinant DNA into mycobacteria by infection with high efficiency (14). A shuttle phasmid, phAE39, was constructed from mycobacteriophage TM4, which forms plaques on both the fastgrowing mycobacterium $M$. smegmatis and the slow-growing mycobacterium M. tuberculosis, by insertion of an $E$. coli cosmid into which the FFlux gene had been inserted downstream of the strong $h s p 60$ promoter (Fig. 2A). A host range mutant of phAE39, phAE40, was isolated that was capable of infecting bacillus Calmette-Guerin (BCG) vaccine strains, in addition to M. smegmatis and M. tuberculosis (Fig. 2A). To test whether these resulting luciferase reporter phages (LRPs) could elicit the production of light after infection of mycobacteria, we mixed the LRPs with M. smegmatis cells and then exposed the mixture at different times to luciferin. Light signals could be detected by means of a luminometer within minutes of infection and increased 1000-fold within 2 hours (Fig. 2B). The signals are two to three orders of magnitude lower than an equivalent number of cells harboring the luciferase plasmids, probably as a result of less efficient gene expression or of inhibitory effects of the phage on host cell metabolism or ATP levels. The similarity of the kinetics of light production in $M$. smegmatis and BCG (Fig. 2B) suggests that differences in gene expression may not be the principal determinant in the tenfold slower growth of BCG (or M. tuberculosis) relative to $M$. smegmatis.

It then became feasible to test whether the luciferase reporter phages were capable of distinguishing drug-resistant from drug-susceptible organisms. Mutants of BCG were selected that were resistant to rifampicin, streptomycin, or isoniazid (Fig. 3). When wild-type BCG and the mutants were cultured for 24 hours with the antibiotics, the parental strain did not produce any signal, whereas light was produced by the drug-resistant mutants (Fig. 3). Finally, the luciferase reporter phage assay was tested on clinically derived $M$. tuberculosis strains, both singly and multiply drug-resistant (MDR). The results (Fig. 4) established that luciferase reporter phages can rapidly reveal the patterns of drug susceptibility or resistance of $M$. tuberculosis strains. The apparent lower activity of M. tuberculosis relative to BCG (Fig. 3) primarily reflects the use of a luminometer with different light unit definition and sensitivity rather than an intrinsic difference between bacterial strains (15).

Because of the emergence of multidrug-resistant strains, it has become increasingly important to rapidly ascertain patterns of drug susceptibility. These observations demonstrate the use of luciferase reporter mycobacteriophages as simple tools for the rapid determination of drug susceptibility profiles of $M$. tuberculosis. It is expected that this methodology will be adapted for use on clinical isolates with a minimum time of culture. This might be achieved by an increase in the sensitivity of the assay or by engineering of better characterized mycobacteriophages, such as L5 [whose complete DNA sequence is known (16)], to permit higher expression of luciferase. The technology could be adapted for use in developing countries either through use of inexpensive luminometers or of sensitive film technology (7). In addition, luciferase phages or $M$. tuberculosis strains expressing luciferase genes may permit rapid screening of drugs for antituberculosis activity.

\section{REFERENCES AND NOTES}

1. C J. L. Murray, K. Styblo, A. Rouillon, in Disease Control Priorities in Developing Countries, D. T. Jamison and W. H. Mosley, Eds. (Oxford Univ. Press for the World Bank, New York, in press); C. J. L. Murray, K. Styblo, A. Rouillon, Bull. 
Int. Union Tuberc. 65, 6 (1990).

2. Y. Abouya et al., Am. Rev Respir. Dis. 145, 617 (1992).

3. T. R. Frieden et al., N. Engl. J. Med. 328, 521 (1993); M. Goble et al., ibid., p. 527; M. D. Iseman and L. A. Madsen, Clin. Chest. Med. 10, 341 (1992); M. D. Iseman and J. A. Sbarbaro, Curr. Clin. Top. Infect. Dis. 12, 188 (1992).

4. L. Heifets, Drug Susceptibility in the Chemotherapy of Mycobacterial Infections, L. Heifets, Ed. (CRC Press, Ann Arbor, MI, 1991), pp. 89-122.

5. Morbid. Mortal Weekly Rep. 41, 507 (1992).

6. J. W. Hastings, T. O. Baldwin, M. Z. Nicoli, Methods Enzymol. 57, 135 (1978).

7. M. A. DeLuca and W. D. McElroy, eds., Bioluminescence and Chemiluminescence (Academic Press, New York, 1981), P E Stanley et al., J. Biolumin. Chemilumin. 3, 131 (1989), G. G. G. Thorpe, T. P. Whitehead, R. Penn, L. J. Dricka, Clin. Chem. 30, 806 (1984).

8. J. R. deWet, K. V. Wood, D. R. Helinski, M. Deluca, Proc. Natl. Acad. Sci. U.S.A. 82, 7870 (1985), J. R. deWet, K. V. Wood, M. DeLuca, D. R. Helinski, S, Subramani, Mol. Cell. Biol. 7, 725 (1987).

9. D. W. Ow et al., Science 234, 856 (1986); J. Gould and S. Subramani, Anal. Biochem. 175, 5 (1988); A. J. Palomeres, M. A. DeLuca, D. R. Helinski, Gene
81, 55 (1989); A. G. Dileia et al., Nucleic Acids Res. 16, 4159 (1988), A. R. Brasier, J. E. Tate, J. F. Habener, BioTechniques 7, 1116 (1989); K. V. Wood, Y. A. Lam, W. D. McElroy, J. Biolumin. Chemilumin. 5, 107 (1990); T. Kondo N. Takahashi, M. Muramatsu, Nucleic Acids Res. 20, 5729 (1992); A. J. Miller, S. R. Short, N. H. Chua, S. A. Kay, Plant Cell 4, 1075 (1992), J. Engebrecht, M. Simon, M. Sherman, Science 227, 1345 (1985); J. J. Shaw and C. J. Kado, BioTechniques 4, 560 (1986), G. Schmetterer, C. P. Wolk, J. Elhai, J. Bacteriol. 167, 411 (1986), O. A Carmi, G. S. A. B. Stewart, S. Ulitzur, J. Kuhn, J. Bacteriol. 169, 2165 (1987).

10. C. K. Stover et al., Nature 351, 456 (1991).

11. M. K. Donnelly-Wu, W. R. Jacobs, Jr., G. F. Hatfull, Mol. Microbiol. 7, 407 (1 993).

12. M. H. Lee, L. Pascopella, W. R. Jacobs, Jr., G. F. Hatfull, Proc. Natl. Acad. Sci. U.S.A. 88, 3111 (1991).

13. S. Ulitzer and J. Kuhn, in Bioluminescence and Chemiluminescence, New Perspectives, J. Sclomerick, R. Andresen, A. Kapp, M. Ernst, W. G. Woods, eds. (Wiley, New York, 1987), pp. 463472; C. P. Kodikara, H. H. Crew, G. S. A. B. Stewart, FEMS Microbiol. Lett. 83, 261 (1991).

14. W. R. Jacobs, Jr., M. Tuckman, B. R. Bloom, Nature 327, 532 (1987); S. B.
Snapper et al., Proc Natl. Acad. Sci. U.S.A. 85, 6987 (1988).

15. W. R. Jacobs, Jr., et al., unpublished data.

16. G. F. Hatfull and G. J. Sarkis, Mol. Microbiol. 7, 395 (1993).

17. S. B. Snapper, R. E. Melton, S. Mustafa, T. Kieser, W. R. Jacobs, Jr., Mol. Microbiol. 4, 1911 (1990).

18. R. G. Barletta et al., unpublished data.

19. W. R. Jacobs, Jr., et al., Methods Enzymol. 204, 537 (1991).

20. Morbid. Mortal. Weekly Rep., in press.

21. We thank J. McKittrick, D. Alland, L. Ornstein, K. Stover, and R. Davis for helpful discussions and R. Good, J. Kilburn, and D. Alland for providing strains. Supported by National Institutes of Health grants A127235 (to W.R.J. and G.F.H) and A128927 (to G.F.H.); National Cooperative Drug Discovery Group grants UOIA130189 (to W.R.J.) and A123545 (to B.R.B.); and grants from the Special Program for Tropical Diseases and Program for Vaccine Development of the World Health Organization (to W.R.J. and B.R.B.).

Submitted January 22, 1993, accepted March 29, 1993. 